\title{
THE IMPACT OF NEW TARGETING METHODS IN THE CANCER THERAPY
}

\author{
ZAKARIYA AL-MASHHADANIa, RUA A. NASERa, MUNAF H. ZALZALA ${ }^{b}$
}

aDepartment of Pharmacology and Toxicology, College of Pharmacy, Mustansiriyah University, Baghdad, Iraq, bepartment of

Pharmacology and Toxicology, College of Pharmacy, University of Baghdad, Baghdad, Iraq

Email: zakariya.mahdi@uomustansiriyah.edu.iq

Received: 24 Nov 2018, Revised and Accepted: 30 Jan 2019

\begin{abstract}
Rapid development has achieved in treating tumor to stop malignant cell growth and metastasis in the past decade. Numerous researches have emerged to increase potency and efficacy with novel methods for drug delivery. The main objective of this literature review was to illustrate the impact of current new targeting methods to other previous delivering systems to select the most appropriate method in cancer therapy. This review first gave a brief summary of cancer structure and highlighted the main roles of targeting systems. Different types of delivering systems have been addressed in this literature review with focusing on the latest carrier derived from malarial protein. The remarkable advantages and main limitations of the later have been also discussed. PubMed and Science Direct were the main search engines that have been used as information sources to prepare this review. Articles related to cancer targeting system, active and passive processes, current nanoparticles, antibody carriers, and current novel cancer carriers were used as sources in this review. Important points from many references published in the last decade (20082018) were selected and included. Several targeting methods were introduced to enhance the efficacy and tolerability of the toxic drug by active and passive processes, but there is still no conclusive carrier without certain drawbacks. A combination of targeting methods probably shows the most appropriate choice for increasing selectivity and safety of anticancer drugs via reducing the concentration of carriers used.
\end{abstract}

Keywords: Cancer, Targeting system, Active process, Passive process, Nanoparticles, Antibody carrier, Malarial protein

(C) 2019 The Authors. Published by Innovare Academic Sciences Pvt Ltd. This is an open-access article under the CC BY license (http://creativecommons.org/licenses/by/4.0/) DOI: http://dx.doi.org/10.22159/ijap.2019v11i2.30979

\section{INTRODUCTION}

Cancer is the second leading cause of death in developed countries after cardiovascular diseases. According to the World Health Organization (WHO), over nine million new cases of cancer were diagnosed each year with a high mortality rate exceeding 9.6 million deaths in 2018 [1]. The past decades have shown a rapid development of cancer therapy to stop the growth and metastasis of the tumor. However, due to the lower selectivity of anticancer drugs to differentiate between malignant and normal cells, serious adverse effects appear as a major issue. Therefore, targeting cancer cells has emerged as a priority of researchers to develop a safe and selective method for delivering the drug directly into the malignant cells [2]. Recently, several studies have attempted to create an ideal method for drug delivery with higher safety and efficacy. The latest research conducted by Salanti et al. has been considered as a unique example of these studies and it will be the focus of this literature review with other novel targeting methods since it suggests a promising targeting system by using selective carriers derived from malarial protein [3].

\section{Search criteria}

Articles related to cancer targeting system, active and passive processes, current nanoparticles, antibody carriers, and current novel cancer carriers were used as sources in this review. Authors selected and took the important points from many references published in 2008-2018.

\section{Cancer structure}

Cancer is a group of diseases characterized by the spread of abnormal cells that have uncontrolled high multiplication rate as a result of alteration, up or down-regulation, in gene expression, which is caused by genetic, epigenetic, or environmental factors [4-6]. The continuous growth of these cells forms a mass in various sizes depending on disease level and the affected tissue. This mass can obtain nutrient from the body by either a passive method, when the cancer size is less than $2 \mathrm{~mm}^{3}$ or from abnormal leaky vasculature with pore size ranging from 100 to $780 \mathrm{~nm}$ which is considered too large compared with normal pore 8-10 $\mathrm{nm}$ [7]. In addition, cancer cells have other features which can be distinguished from normal cells, such as dedifferentiation properties combining with loss of usual action, penetrability, and metastasis action to affect other tissues [4].

The past decades have seen rapid development in cancer therapy with powerful cytotoxic drugs in order to stop cell proliferation and treat this disease. However, because cancer and some normal cells share the same internal components, the rest of the body can be affected by these drugs resulting in serious side effects that can lead to suspending many treatment regimens. These adverse effects include bone marrow toxicity, delay in wound healing, hair loss, growth retardation in children, teratogenicity, and carcinogenicity as a result of the mutagenic effect of drugs $[4,5]$. For this reason, it is imperative to minimize unwanted effects by creating a new delivering system to increase the selectivity and bioavailability of anticancer drugs at the site of action.

\section{Role of targeting system}

The past thirty years have seen progressively rapid developments in the field of targeted anticancer drugs. The baseline of this field depends mainly on two major methods, passive and active process $[2,7-11]$. The former relates directly to the nature of tumor capillary vessels, and the later depends on the interaction mechanism with cancer cells. In terms of the passive technique, researchers developed a special type of carrier molecules, which have a particle size larger than normal pore in the non-cancerous vasculature. Consequently, these molecules have a higher tendency to accumulate specifically in tumor mass rather than the rest of the body as a result of the high leaky vasculature in the tumor site [7]. In addition, due to the lack of a clearly defined lymphoid system in cancer tissue, carrier molecules tend to reside in the tumor mass for a long period of time [8]. The combination of the above reasons can explain the delivery system of the passive method and the possibility to increase drug selectivity. However, the selectivity degree of this method is still, clinically, under expectation and more improvements are needed to achieve full activity.

On the other hand, the active method was introduced to overcome some difficulties of the passive technique and optimize the targeting level of anticancer drugs. This method was divided into two major groups: targeting that depends on the direct interaction between carrier and cancer cells and that, which uses physical signals as the main part of the system $[10,11]$. In the active interaction process, carrier molecules have been designed to interact with cancer cells directly by either an antigen-antibody reaction or ligand-receptor pathway $[2,12]$. Folate receptors, for instance, may be highly expressed in cancer cells compared with normal tissue due to high folate required for tumor growth. By a combination of folic acid with targeting molecules in vivo, the efficacy of anticancer drugs can 
increase into 10 folds with a significant reduction in the systemic toxicity [8, 13]. These results encourage researchers to develop similar methods and examine different additional enhancements to optimize the targeting technique.

Recently, with the application of cutting-edge technology and extended research, the physical signals system has emerged as a promising improvement. One example of these systems is by developing new particles with a heat sensor that have a tendency to be permeable when the temperature exceeds $42 \mathrm{C}^{\circ}$ that mainly occurs in cancer tissue. After that, the drug can be specifically released at that site [14-17]. In some circumstances, using hyperthermic agents to elevate the temperature of the targeting tissue or applying an external source of heat such as ultrasound or electromagnetic power could have extra beneficial effects to ensure the process of the drug release [14]. Similar to thermal field design, the additional magnetic molecule or use of polymers with magnetic properties in the synthesis of carrier molecules is showing additional advantages in the targeting process after applying external magnetic field [18-20]. However, although these methods seem to be the best solution to avoid the unwanted effects of anticancer drugs, there are some limitations that need to be considered to choose the most appropriate carrier molecule.

\section{Types of targeting carriers}

\section{- Nanoparticles}

Nanocarriers, the largest group of the targeting system, have been introduced to increase the bioavailability, selectivity, and tolerability of anticancer drugs. They are characterized by a colloidal structure with a particle size ranging from 10 to $1000 \mathrm{~nm}[7,17,21-23]$. Nanoparticles have been designed to accept drug molecules by dissolving, attaching, encapsulating or by the entrapping process and delivering them directly to the site of action by the passive method [21, 24]. There are several types of these particles depending on their method of preparation, such as liposomes, micelles, nanospheres, nanocapsules, and dendrimers, as shown in fig. $1[11,17]$. Liposomes represent the most important nanoparticles with wide applications in cancer therapy. They are composed of two double layers of lipid surrounding an aqueous matrix and having a large particle size to ensure accumulation in the cancer tissue $[23,25,26]$. This unique composition gives liposomes the capability to carry different types of molecules with different chemical nature. Once the carrier reaches the site of action, it disintegrates and liberates drug molecules as a result of interstitial pressure inside the cancer tissue $[27,28]$.

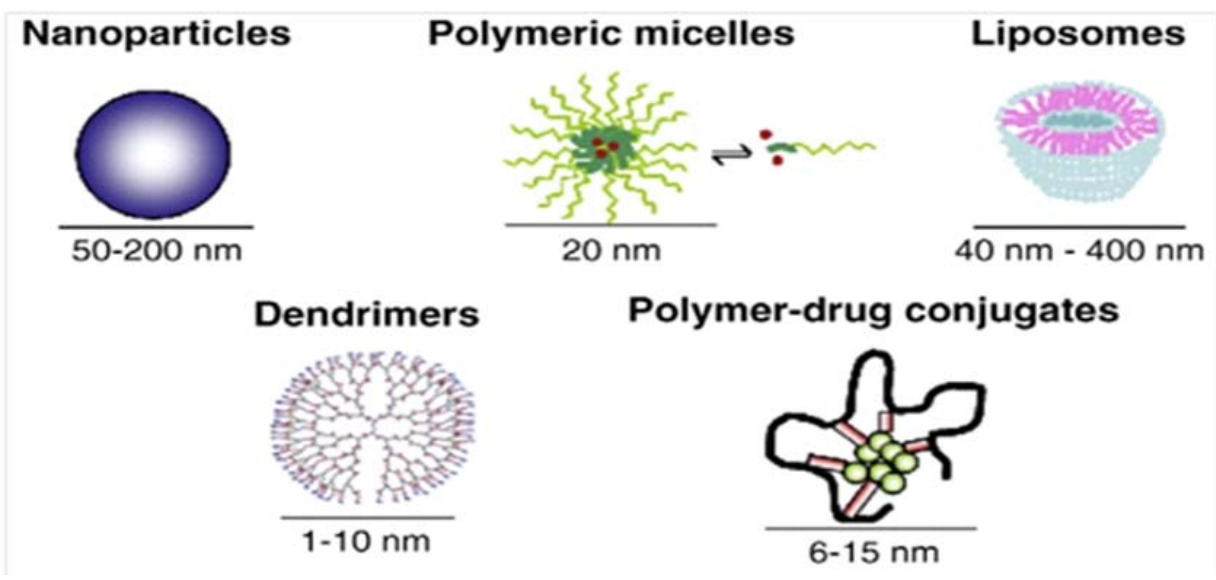

Fig. 1: Types of nanoparticles [11]

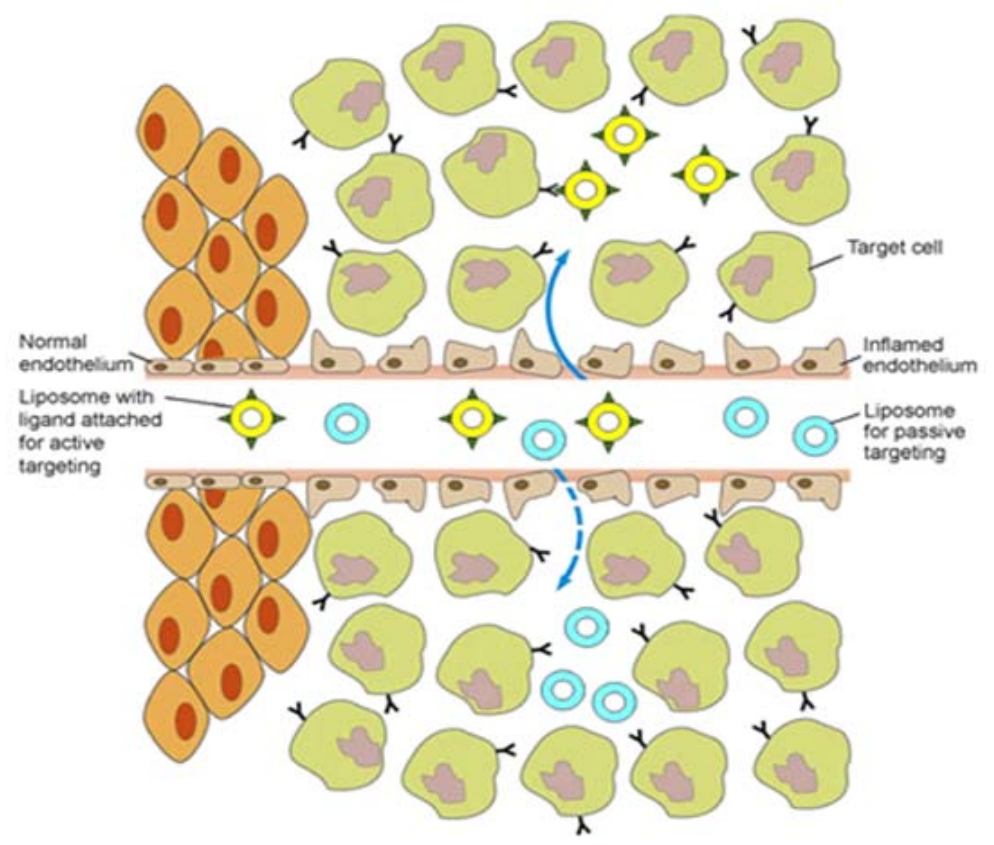

Fig. 2: Passive and active targeting methods by using nanoparticles [29] 
However, liposomes could remain in circulation for a short period due to rapid elimination via the reticular endothelial system (RES). Moreover, electrostatic and hydrophobic power in the liposomes might result in structural collapse [7]. For these reasons, a large number of studies have introduced to increase the selectivity of nanoparticles by incorporating physical signal active methods with the current passive one (fig. 2) [9, 13-15, 17, 18]. In general, even though the combination of methods could accumulate nanoparticles at the site of action and decrease the side effects of anticancer drugs, the therapeutic efficacy still has some concerns. This might be due to the lack of assurance of releasing the drug from the carriers into the interstitial fluid and reaching the cancer cells [15]. That is why it is necessary to expand knowledge and researches to develop this method and add extra techniques to increase drug efficacy.

\section{- Antibodies}

Antibody-drug conjugates system (ADCs) has appeared as a promising active method in targeting cancer and has been developed to overcome some issues of efficacy in nanoparticles [30]. Previously, antibodies were discovered and cloned for use in cancer therapy by different mechanisms, such as a direct toxic effect [31] or indirect stimulation of body immunity [32]. The high specificity of antibodies in targeting tumor cells' antigen and their ability to accept extra molecules by conjugation process open new fields toward researchers to develop a novel delivering system. The system is composed of three important elements: monoclonal antibody (mAb), high potent toxic molecules and a stable linker (fig. 3) [30, 32-34]. Interestingly, several drug molecules can attach single mAb by numerous linkers which increase the possibility to accumulate a high concentration of toxic agent at the site of action [35].

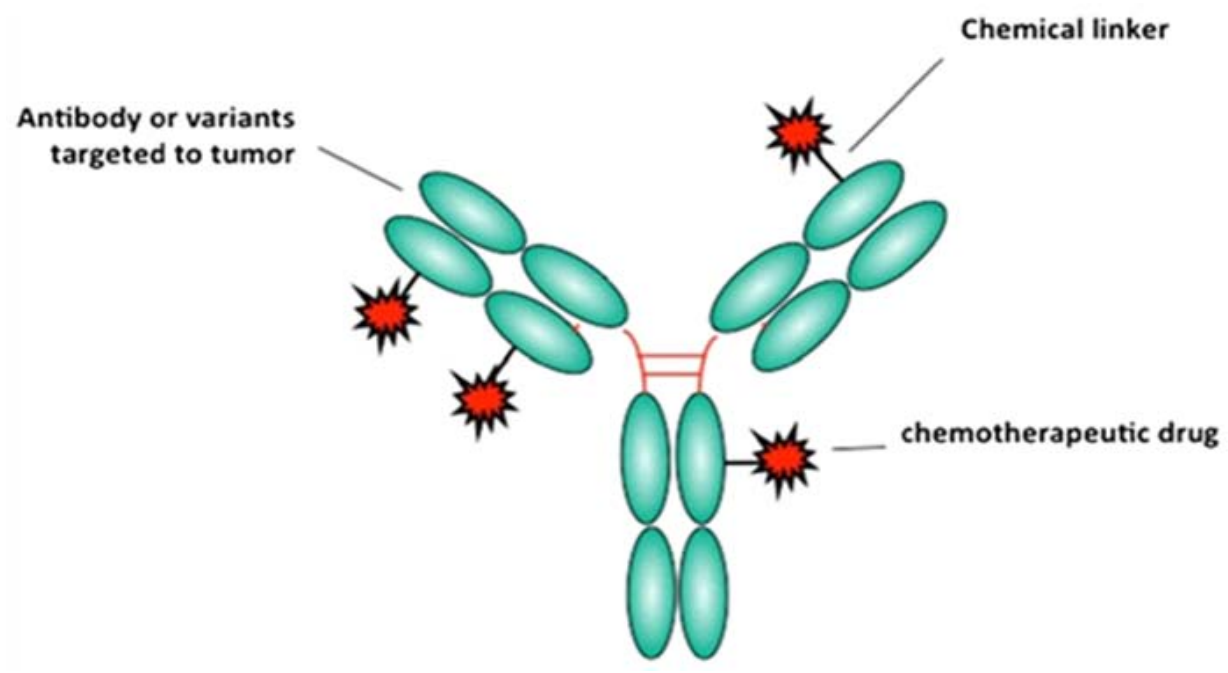

Fig. 3: Structure of the ADSs [36]

The main mechanism of ADCs depends on direct interaction and complex formation of mAb and particular antigen, a protein produced on the surface membrane of cancer. This complex internalizes from the membrane into the cells and undergoes degradation by cellular lysosomal activity to break down the chemical linker and liberate free toxic molecules (fig. 4) [30]. Generally, cancer cells have a tendency to express antigen in higher proportion compared with the rare amount in normal cells [32,33]. Therefore, a large number of studies conducted to discover specific antibodies for these antigens and initiate the reaction for optimum targeting. In the previous decades, over 20 antibodies have been discovered and used to develop a powerful anticancer drug [37]. Brentuximab Vedotin (Adcetris), Trastuzumab-DM1 (Kadcyla), and Gemtuzumab Ozogamicin (Mylotarg) are considered as main examples of approved drugs that used ADCs technique for treating Hodgkin lymphoma, breast cancer, and acute myeloid leukemia, respectively $[33,36,38]$.

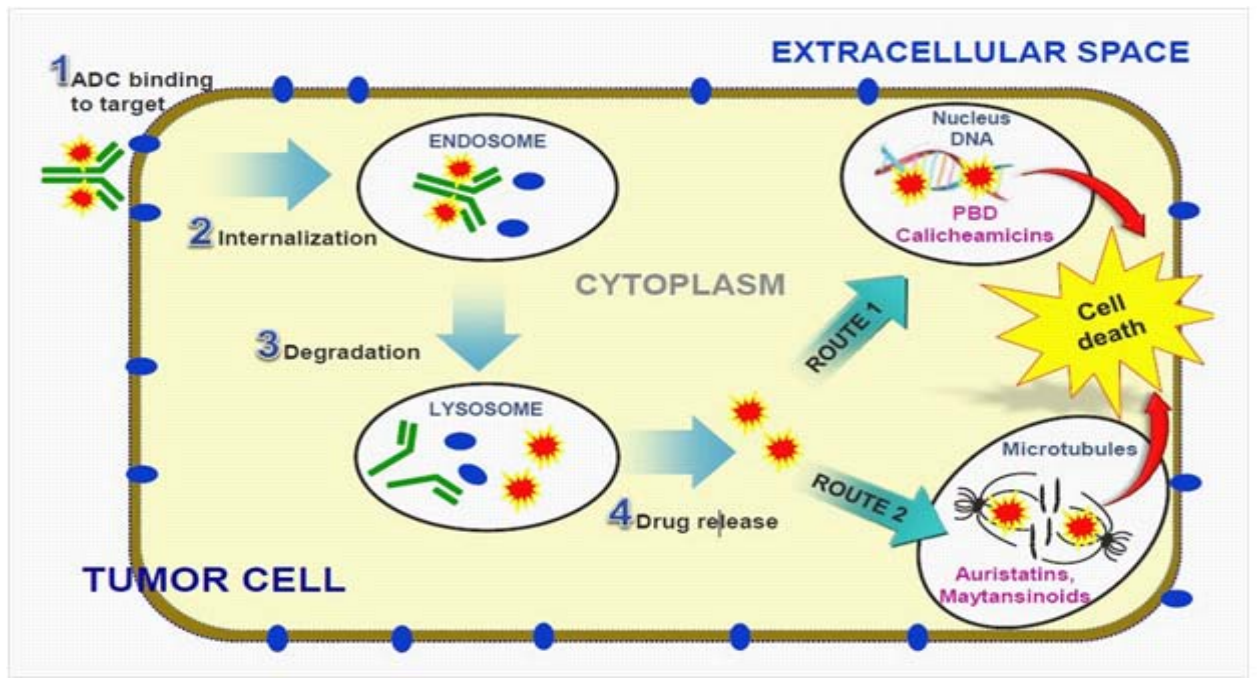

Fig. 4: The mechanism of ACDs [38] 
Serious side effects have emerged after using these drugs ranging from chills and fever to leukopenia and an increase in the mortality rate which resulted in the withdrawal of Mylotarg from the market in 2010 [39]. The reason might be due to the ability of antibodies to express high antigenicity and toxic effects inside the body when used in large doses. Consequently, current researches attempt to increase the safety of ACDs by reducing the dose of antibody and using very potent suspended toxic molecules to compensate for the efficacy of the original drugs [10]. Another considerable issue that has appeared is related to the amount of suspending drug molecules for each $\mathrm{mAb}$ and the type of linker. Nevertheless, increasing attached drugs leads to a decrease in the binding ability of mAb with the targeted antigen which can lose its activity as a consequence [35]. Additionally, an inappropriate type of linker can either prevent dissociation of the drug inside cells or cause association failure through circulation [38]. Therefore, in order to avoid the above problems, it is necessary to choose the suitable binder type and determine the amount of drugs carried by the vehicle carefully. Further researches are also needed in order to increase the stability and safety of ADCs.

\section{- Malaria carrier protein}

Researchers continue screening for an alternative carrier to avoid limitations of current targeting systems. A purified recombinant protein called VAR2CSA (rVAR2) represents one example of the recent vehicles which might have a role in the future for cancer therapy. This protein derived from erythrocyte cells were infected by an engineered modified malaria parasite (Plasmodium falciparum) [3]. During malaria infection, the parasite tends to produce this kind of proteins on the external layer of infected erythrocytes as a defense mechanism to avoid elimination by the clearance process of the body in the spleen [40]. VAR2 proteins have high adhesion properties, which enable the erythrocyte to attach intensely into the interstitial tissues by special receptors called chondroitin sulfate glycosaminoglycan (CSA). Although these receptors expressed in various sites of the human body, studies showed that malaria bind specifically to the placenta tissue by definite subtype of CS (pl-CSA) [41, 42].

So far, placental cells have been proposed to have similar characteristics of cancer cells due to their higher ability of proliferation and invasion of other tissues. Consequently, there are many attempts carried out to evaluate the relationship between these cells to understand the nature of cancer development and the ability of the body to control overproduction of placenta cells [3, 43]. The recent study conducted by Salantni et al. showed that cancer cells express the same receptor of pl-CS in the plasma membrane or in the surrounding stroma of various tumor tissues with a high proportion. They examined a large number of different kinds of cancer cell lines and found approximately $95 \%$ of them interact with rVAR2 with variable affinities. Interestingly, this interaction can be reversed by the addition of soluble CSA to the cultures due to the competition mechanism, which showed that the binding of rVAR2 is concentration dependent [3]. These results have encouraged researchers to further investigate the ability of rVAR2 in targeting cancer cells in vivo and delivering anti-cancer drugs directly at the site of action.

To examine the targeting ability of rVAR2, diphtheria toxin associated with rVAR2 (rVAR2-DT) by a diffusion process was used as a targeting system to investigate the efficacy of malarial proteins in both in vitro and in vivo cancer models. The in vitro studies showed a remarkable effect of rVAR2-DT to kill epithelial and mesenchymal cancer cells with no effect on normal human cells. These studies supported by in vivo researches used mice models which revealed that the rVAR2-DT has a high selectivity to deliver the toxic drug into various types of tumor tissues, such as prostate cancer, with the absence of toxicity effects on the normal tissue [3]. However, this selectivity is concentration dependent and a higher amount of diphtheria toxin is needed to produce anticancer effects. According to the previous clinical trials, the higher concentration of this toxin is not well tolerated by the human body [3]. Therefore, researchers attempted to reduce the dose of incorporating a toxic agent to increase drug tolerability and eliminate side effects.
To avoid the higher concentration issue, researchers developed a new targeting system that incorporates rVAR2 with a potentially toxic agent called as KT886, an analog of hemiasterlin toxin, by a special protease linker [3]. The KT886 toxin is modified antimitotic peptide derived from the marine sponge extract which has a higher potency than diphtheria toxin [44]. The rVAR2-KT886 system can carry more than one molecule of KT886 without disturbing the integrity to produce optimum toxic effects into the site of action with lower concentration. This system showed a potent and selective in vivo cytotoxicity to different tumor tissues containing pl-CS receptors with no detectable side effects. Moreover, the study measured the proportion of internalizing molecule into cancer cells and demonstrated that the rVAR2-KT886 has a high penetration rate and delivering toxic drug internally into cancer cells [3]. Depending on these impressive results, it seems that rVAR2 might be a prospective alternative method to the other current targeting carriers in treating cancer.

Although the remarkable targeting results of the rVAR2 in the previous study, there are some concerns about the safety of this system in human. The reason is related to the period of previous investigations were conducted for $14 \mathrm{~d}$ which seems to be insufficient to evaluate the full safety profile in normal tissues. In addition, the investigation of immunogenic and resistant effects is particularly unsuitable to validate with this short period study, which needs more time to progress. According to the European Medicines Agency (EMA), anticancer drugs need more than three months period of nonclinical study for toxicological evaluation prior to developing any clinical trials [45]. Therefore, extended in vivo studies are required to provide a valid picture for ensuring the use of these proteins safely in human patients.

Besides the safety concern, the efficacy profile of the rVAR2-KT886 system seems to be another aspect that needs to be considered. As with the ADCs, the stability of linkers that used in the rVAR2 technique might disturb and undergo dissociation process after direct exposure to the human blood circulation. Hence, evaluating the type of linkers and balancing the amount of suspending toxic drugs are essential to avoid any limitation which might result in the targeting system collapse.

Another issue with the Salanti et al. study was related to the fact that the researchers used only mice as a model without considering the other in vivo models [3]. For instance, rats and rabbits are needed to exclude any genetic factors. The particular genetic difference between mice and humans might be responsible for variation in the immunity system, stress response, and metabolic process [46]. Therefore, further researches in different models are required to examine the safety and efficacy of rVAR2 system prior to establishing any clinical trials in the future.

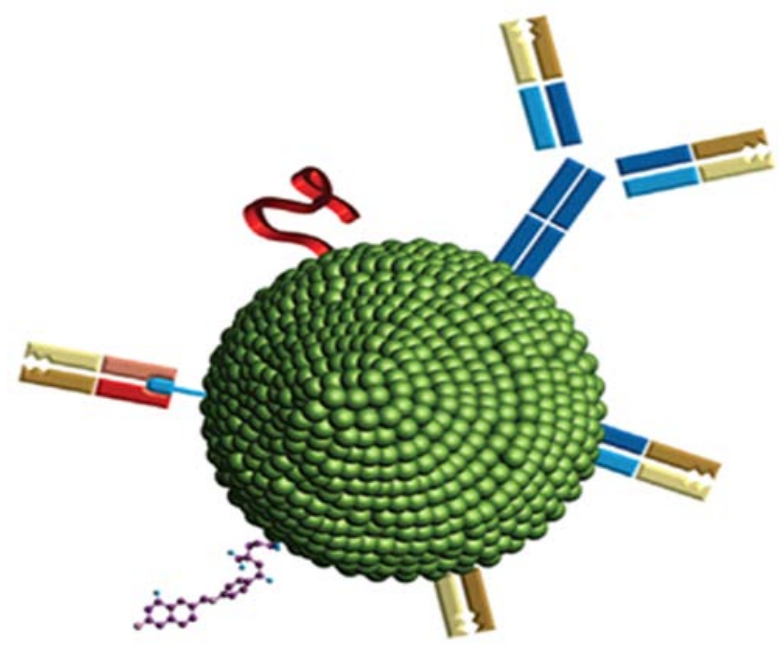

Fig. 5: A combination of nanoparticle with antibodies and other active ligands [47] 


\section{- New approach: combination system}

Despite the particular drawbacks for previous carriers, researchers have examined methods to combine different targeting systems for synergistic benefits. Depending on the current carriers and with accumulative knowledge, many encouraging studies have been developed to afford new opportunity to improve the safety and selectivity of vehicles. For instance, the combination of nanoparticles with antibodies introduces maximum advantages with higher safety and selectivity than each carrier alone (fig. 5) [47-50]. This combination depends on the capability of nanoparticles to carry a large number of toxic drugs and the ability of antibodies to provide these drugs specifically into the site of action through the endocytosis mechanism [47]. Consequently, the side effects of carriers will decrease as a result of a reduction in the concentration of vehicles required for delivery. New prospect studies can be emerged from this finding to investigate other alternatives and compare the activity to choose the most appropriate combination. Accordingly, the rVAR2 proteins that showed a higher selectivity in the initial in vivo studies seem to be a suitable alternative to examine their activity with nanoparticles or other carriers in the prospective clinical trials to create a useful vehicle with minimum side effects.

\section{CONCLUSION}

In the last three decades, significant developments have been achieved with the targeting cancer approaches. Different carriers using various mechanisms, active and passive methods, have appeared as promising vehicles to increase the efficacy of anticancer drugs and reduce their unwanted effects. The recent vehicle derived from the malaria protein, rVAR2, represents the main example of these carriers that showed a high selectivity in cancer in vivo studies and a significant reduction in the adverse effects of the suspending toxic drugs. The aim of this literature was to evaluate the impact of new carriers compared to the other systems and select the best one to be used in cancer therapy. Although the diversity of targeting methods could enhance the efficacy and tolerability of the toxic drug, there is no definitive carrier without certain drawbacks. Depending on the current evidence, the combination method of different vehicles in one system might be the most appropriate choice to increase the selectivity and safety of anticancer drugs by reducing the concentration of carriers used. However, substantial researches are still needed to be dedicated to the targeting field in order to exploit the safest and most applicable vehicle option.

\section{AUTHORS CONTRIBUTIONS}

All the author have contributed equally

\section{CONFLICT OF INTERESTS}

\section{Declared none}

\section{REFERENCES}

1. World Health Organization. Cancer fact statistic; 2018. Available from: http://www.who.int/news-room/factsheets/detail/cancer [Last accessed on 15 Sep 2018]

2. Muhamad N, Plengsuriyakarn T, Na-Bangchang K. Application of active targeting nanoparticle delivery system for chemotherapeutic drugs and traditional/herbal medicines in cancer therapy: a systematic review. Int J Nanomed 2018;13:3921-35.

3. Salanti A, Clausen TM, Agerbaek MO, Al Nakouzi N, Dahlback M, Oo HZ, et al. Targeting human cancer by a glycosaminoglycan binding malaria protein. Cancer Cell 2015;28:500-14.

4. Rang HP, Ritter J, Flower RJ, Henderson G. Rang, and dale's pharmacology. Edinburgh: Elsevier Churchill Livingstone; 2016.

5. Hassanpour SH, Dehghani M. Review of cancer from the perspective of molecular. J Cancer Res Practice 2017;4:127-9.

6. Ke X, Shen L. Molecular targeted therapy of cancer: the progress and future prospect. Frontiers Lab Med 2017;1:69-75.

7. Haley B, Frenkel E. Nanoparticles for drug delivery in cancer treatment. Urol Oncol: Semin Orig Invest 2008;26:57-64.

8. Byrne JD, Betancourt T, Brannon-Peppas L. Active targeting schemes for nanoparticle systems in cancer therapeutics. Adv Drug Delivery Rev 2008;60:1615-26.
9. Li L, Di X, Wu M, Sun Z, Zhong L, Wang Y, et al. Targeting tumor highly-expressed LAT1 transporter with amino acid-modified nanoparticles: Toward a novel active targeting strategy in breast cancer therapy. Nanomedicine 2017;13:987-98.

10. Yokoyama M. Drug targeting with nano-sized carrier systems. J Artif Organs 2005;8:77-84.

11. Danhier F, Feron 0, Preat V. To exploit the tumor microenvironment: Passive and active tumor targeting of nanocarriers for anti-cancer drug delivery. J Controlled Release 2010;148:135-46.

12. Sau S, Alsaab HO, Kashaw SK, Tatiparti K, lyer AK. Advances in antibody-drug conjugates: a new era of targeted cancer therapy. Drug Discovery Today 2017;22:1547-56.

13. Patil Y, Shmeeda H, Amitay Y, Ohana P, Kumar S, Gabizon A. Targeting of folate-conjugated liposomes with co-entrapped drugs to prostate cancer cells via prostate-specific membrane antigen (PSMA). Nanomed: Nanotechnol Biol Med 2018; $14: 1407-16$

14. Lei T, Manchanda R, Fernandez-Fernandez A, Huang YC, Wright $\mathrm{D}$, McGoron AJ. Thermal and $\mathrm{pH}$ sensitive multifunctional polymer nanoparticles for cancer imaging and therapy. Res Adv 2014;4:17959-68.

15. Koning GA, Eggermont AMM, Lindner LH, Ten Hagen TLM. Hyperthermia and thermosensitive liposomes for improved delivery of chemotherapeutic drugs to solid tumors. Pharm Res 2010;27:1750-4.

16. Dicheva BM, Koning GA. Targeted thermosensitive liposomes: an attractive novel approach for increased drug delivery to solid tumors. Expert Opin Drug Delivery 2014;11:83-100.

17. Sawant RR, Torchilin VP. Liposomes as 'smart' pharmaceutical nanocarriers. Soft Matter 2010;6:4026-44.

18. Misra RDK. Magnetic nanoparticle carrier for targeted drug delivery: perspective, outlook, and design. Mater Sci Technol 2008;24:1011-9.

19. Bi H, Han X. Magnetic field triggered drug release from lipid microcapsule containing lipid-coated magnetic nanoparticles. Chem Phys Lett 2018;706:455-60.

20. Hoop M, Ribeiro AS, Rösch D, Weinand P, Mendes N, Mushtaq F, et al. Mobile magnetic nanocatalysts for bioorthogonal targeted cancer therapy. Adv Funct Mater 2018;28:7354-61.

21. Kadam VB, Dhanawade KB, Salunkhe VA, Ubale ATAT. Nanoparticle-novel drug delivery system. Curr Pharma Res 2014;4:1318-35.

22. Kadian R. Nanoparticles: a promising drug delivery approach. Asian J Pharm Clin Res 2018;11:30-5.

23. Pawar HR, Bhosale SS, Derle ND. Use of liposomes in cancer therapy: a review. Int J Pharm Sci Res 2012;3:3585-90.

24. Aravinthrajkumar G, Gayathri R, Vishnupriya V. Targeting the target using nanoparticles-a review. Asian J Pharm Clin Res 2017;10:6-10.

25. Zununi Vahed S, Salehi R, Davaran S, Sharifi S. Liposome-based drug co-delivery systems in cancer cells. Mater Sci Eng C 2017;71:1327-41.

26. Belfiore L, Saunders DN, Ranson M, Thurecht KJ, Storm G, Vine KL. Towards clinical translation of ligand-functionalized liposomes in targeted cancer therapy: challenges and opportunities. J Controlled Release 2018;277:1-13.

27. Singh RP, Gangadharappa HV, Mruthunjaya K. Phospholipids: Unique carriers for drug delivery systems. J Drug Delivery Sci Technol 2017;39:166-79.

28. Li J, Wang X, Zhang T, Wang C, Huang Z, Luo X, et al. A review on phospholipids and their main applications in drug delivery systems. Asian J Pharm Sci 2015;10:81-98.

29. Malam Y, Loizidou M, Seifalian AM. Liposomes and nanoparticles: nanosized vehicles for drug delivery in cancer. Trends Pharmacol Sci 2009;30:592-9.

30. Dan N, Setua S, Kashyap KV, Khan S, Jaggi M, Yallapu MM, et al. Antibody-drug conjugates for cancer therapy: chemistry to clinical implications. Pharmaceuticals 2018;11:32.

31. Houot R, Kohrt HE, Marabelle A, Levy R. Targeting immune effector cells to promote antibody-induced cytotoxicity in cancer immunotherapy. Trends Immunol 2011;32:510-6.

32. Polakis P. Antibody-drug conjugates for cancer therapy. Pharmacol Rev 2016;68:3-19. 
33. Alley SC, Okeley NM, Senter PD. Antibody-drug conjugates: targeted drug delivery for cancer. Curr Opin Chem Biol 2010;14:529-37.

34. Jerjian TV, Glode AE, Thompson LA, O'Bryant CL. Antibodydrug conjugates: a clinical pharmacy perspective on emerging cancer therapy. Pharmacotherapy 2016;36:99-116.

35. Goli N, Bolla PK, Talla V. Antibody-drug conjugates (ADCs): Potent biopharmaceuticals to target solid and hematological cancers-an overview. J Drug Delivery Sci Technol 2018;48:106-17.

36. Lin K, Tibbitts J. Pharmacokinetic considerations for antibody drug conjugates. Pharm Res 2012;29:2354-66.

37. Reichert JM. Monoclonal antibodies as innovative therapeutics. Curr Pharm Biotechnol 2008;9:423-30.

38. Kim EG, Kim KM. Strategies and advancement in antibody-drug conjugate optimization for targeted cancer therapeutics. Biomol Ther 2015;23:493-509.

39. US Food and Drug Administration. Pfizer voluntarily withdraws cancer treatment Mylotarg from U. S. Market; 2010. Available from: http://www.fda.gov/NewsEvents/Newsroom/Press Announcements/ucm216448.htm. [Last accessed on 15 Sep 2018].

40. Baruch DI, Pasloske BL, Singh HB, Bi X, Ma XC, Feldman M, et al. Cloning the P. falciparum gene encoding PfEMP1, a malarial variant antigen and adherence receptor on the surface of parasitized human erythrocytes. Cell 1995;82:77-87.

41. Salanti A, Staalsoe T, Lavstsen T, Jensen ATR, Sowa MPK, Arnot $\mathrm{DE}$, et al. Selective upregulation of a single distinctly structured var gene in chondroitin sulphate a-adhering plasmodium falciparum involved in pregnancy-associated malaria. Mol Microbiol 2003;49:179-91.

42. Salanti A, Dahlbäck M, Turner L, Nielsen MA, Barfod L, Magistrado P, et al. Evidence for the involvement of VAR2CSA in pregnancy-associated malaria. J Exp Med 2004;200:1197-203.
43. Ferretti C, Bruni L, Dangles Marie V, Pecking AP, Bellet D. Molecular circuits shared by placental and cancer cells, and their implications in the proliferative, invasive and migratory capacities of trophoblasts. Hum Reprod Update 2007;13:121-41.

44. Tuyet Anh Dang T, Chinh Pham T, Quoc Anh N, Thu Ha Vu T, Tien Dung N, Duy Tien D, et al. Synthesis of new bioisosteric hemiasterlin analogues with extremely high cytotoxicity. Bioorg Med Chem Lett 2014;24:5216-8.

45. European Medicines Agency. ICH S9 guideline on nonclinical evaluation for anticancer pharmaceuticals-questions and answers; 2018. Available from: http://www.ema.europa.eu/ docs/en_GB/document_library/Scientific_guideline/2018/05/ WC500248965.pdf [Last Accessed on 16 Sep 2018].

46. National Institutes of Health. Comparing the Mouse and Human Genomes; 2014. Available from: http://www.nih.gov/newsevents/nih-research-matters/comparing-mouse-humangenomes. [Last Accessed on 16 Sep 2018]

47. Goodall S, Jones ML, Mahler S. Monoclonal antibody-targeted polymeric nanoparticles for cancer therapy-future prospects. J Chem Technol Biotechnol 2015;90:1169-76.

48. Alibakhshi A, Abarghooi Kahaki F, Ahangarzadeh S, Yaghoobi H, Yarian F, Arezumand R, et al. Targeted cancer therapy through antibody fragments-decorated nanomedicines. J Controlled Release 2017;268:323-34.

49. Son S, Shin S, Rao NV, Um W, Jeon J, Ko H, et al. Anti-trop2 antibody-conjugated bioreducible nanoparticles for targeted triple negative breast cancer therapy. Int J Biol Macromol 2018;110:406-15.

50. Zhang Y, Guo J, Zhang XL, Li DP, Zhang TT, Gao FF, et al. Antibody fragment-armed mesoporous silica nanoparticles for the targeted delivery of bevacizumab in ovarian cancer cells. Int J Pharm 2015;496:1026-33. 